\title{
La poesía negra de expresión brasileña en la consolidación de la identidad nacional
}

Doctora María de Lourdes Otero Brabo Cruz ${ }^{24}$

Assis, São Paulo, BRASIL

Cuando pensamos en la poesía negra de expresión brasileña, de pronto nos llega la imagen de Castro Alves (1847-1871), el poeta baiano abolicionista, perteneciente a la tercera generación del Romanticismo, conocida como condorera o hugoniana, direccionada a la poesía social. Poesías como Vozes d’África o Navio Negreiro son clásicos de 1869, que tuvieron también su papel de enfrentamiento, de encorajar hacia la lucha por la libertad de los negros en el país, de denunciar la llaga abierta de la esclavitud que es, finalmente, abolida en 13 de mayo de 1888.

E existe um povo que a bandeira empresta

Pra cobrir tanta infâmia e cobardia!...

E deixa-a transformar-se nessa festa

Em manto impuro de Bacante fria!...

Meu Deus! Meu Deus! Mas que bandeira é esta,

Que impudente na gávea tripudia?!...

Silêncio! Musa! Chora, e chora tanto

Que o pavilhão se lave no teu pranto!...

Auriverde pendão de minha terra,

Que a brisa do Brasil beija e balança,

Estandarte que à luz do sol encerra

$\mathrm{E}$ as promessas divinas da esperança...

Tu que, da liberdade após a guerra,

Foste hasteado dos heróis na lança,

Antes te houvessem roto na batalha,

Que servires a um povo de mortalha!

(fragmento de Navio Negreiro - Castro Alves)

\author{
!Y hay un pueblo que su bandera presta \\ Para cubrir tanta infamia y cobardía!... \\ Y la deja transformarse en esa fiesta \\ !En manto impuro de Bacante fría!... \\ !Dios mío! !Dios mío! Mas ¿qué bandera es esta, \\ Que impúdica en el mástil humilla?!... \\ !Silencio! !Musa! Llora, y llora tanto \\ !Qué el pabellón se lave en tu llanto!... \\ Verde amarillo pendón de mi tierra, \\ Que la brisa del Brasil besa y balanza, \\ Estandarte que a la luz del sol encierra \\ Y las promesas divinas de la esperanza... \\ Tú que, de la libertad tras la guerra, \\ Fuiste enarbolado por los héroes en la lanza, \\ Antes te hubiesen roto en la batalla, \\ A que sirvieras a un pueblo de mortaja! \\ (Barco de Esclavos. Trad. Malu Otero y Fredy Valiente)
}

Luis Gama (1830-1882), también baiano de nacimiento, ha sido el primer gran líder negro en São Paulo. Hijo de un hidalgo portugués y una negra liberta, fue vendido por el padre cuando tenía diez años de edad. Según Damasceno (1988:44) él ha sido, como poeta lírico, el primer negro brasileño a cantar su amor por una mujer de la misma raza. 


\begin{tabular}{|c|c|}
\hline $\begin{array}{l}\text { "Meus amores são lindos, cor } \\
\text { da noite } \\
\text { Recamada de estrelas rutilan- } \\
\text { tes; } \\
\text { São formosa crioula ou Tehtis } \\
\text { negra, } \\
\text { Tem por olhos dois astros ru- } \\
\text { tilantes. } \\
\text { (Poeta Luis Gama) }\end{array}$ & $\begin{array}{l}\text { "Mis amores son lindos, co- } \\
\text { lor } \\
\text { de la noche } \\
\text { Recamada de estrellas ruti- } \\
\text { lantes; } \\
\text { Son hermosa criolla o Tehtis } \\
\text { negra, } \\
\text { Sus ojos son dos astros ruti- } \\
\text { lantes. } \\
\text { (Trad. Malu Otero y Fredy } \\
\text { Valiente) }\end{array}$ \\
\hline
\end{tabular}

Se reconoce el talento de este poeta, que ha actuado como abogado abolicionista y ha sido miembro de la Academia de Letras Paulista. Su producción lírica satírica presentó una crítica de la sociedad de la época y el prejuicio hacia el negro. Muy conocida la sátira "Quem sou eu?" también conocida como "Bodarrada" donde utiliza el término despectivo negro o bode, para revertir la utilización prejuiciosa de la sociedad vigente:

\begin{tabular}{l|l}
$\begin{array}{l}\text { Se negro sou, ou sou bode, } \\
\text { Pouco importa, O que isto } \\
\text { pode? }\end{array}$ & $\begin{array}{l}\text { Si yo soy negro o soy chivo, } \\
\text { Poco importa, ¡He dicho! } \\
\text { Hay chivos de toda casta, }\end{array}$ \\
$\begin{array}{l}\text { Pois que a espécie é muito } \\
\text { vasta... }\end{array}$ & $\begin{array}{l}\text { Pues la especie es muy vasta... } \\
\text { Los hay grises, los hay atigra- } \\
\text { dos }\end{array}$ \\
$\begin{array}{l}\text { Há cinzentos, há rajados, } \\
\text { Baios, pampas e malhados } \\
\text { Bodes negros, bodes bran- } \\
\text { cos, }\end{array}$ & $\begin{array}{l}\text { Chivos negros, chivos blancos, } \\
\text { Y, seamos todos francos, }\end{array}$ \\
$\begin{array}{l}\text { E, sejamos todos francos, } \\
\text { Uns plebeus e outros nobres }\end{array}$ & $\begin{array}{l}\text { Unos plebeyos y otros nobles } \\
\text { Chivos ricos, chivos pobres } \\
\text { Chivos sabios, importantes, } \\
\text { Y también algunos maleantes... } \\
\text { Bodes sábios, importantes, } \\
\text { E também alguns tratantes... } \\
\text { Aqui, nesta boa terra, en esta buena tierra, } \\
\text { Marram todos, tudo berra. } \\
\text { Chiflan todos, todo bala. }\end{array}$ \\
$\begin{array}{l}\text { Poeta Luis Gama) } \\
\text { (Trad. Malu Otero y Fredy Va- }\end{array}$
\end{tabular}

Avanzando en el tiempo, tenemos los movimientos de vanguardia, que repercuten a partir de la Semana de Arte Moderna de 1922, en São Paulo. El énfasis del grupo paulista está en el retorno a las raíces, con una vertiente indigenista (Manifiesto Pau Brasil y Manifiesto Antropofágico). En Minas Gerais (BH) surge el periódico "leite criôlo" que buscaba agregar la cultura africana a la formación de nuestra identidad (1er ejemplar en 13 de mayo de 1929). En aquel momento, el pensamiento dominante en el Brasil era de que el negro era inferior y lo asociaban a los "males de la nacionalidad" como lujuria, codicia, tristeza y pereza. Según Damasceno (1988:59) afirma acerca de ese periódico:
"Leite Criôlo representa el primer intento de poesía negra que se conoce dentro del "Modernismo", iniciando el empleo de recursos más tarde usados en la reproducción de los ritmos negros como la aliteración, la homofonía por la secuencia de los sonidos nasales y cerrados. Una de las formas encontradas por los poetas de Leite Criôlo para enseñar al negro la necesidad de combatir los prejuicios y estereotipos a través de la modificación del comportamiento negativo a él atribuido "obedece a una estrategia agresiva, una especie de tratamiento de choque" (Bueno, 1979:150). Ese tratamiento de choque se traduce por el recuerdo de los sufrimientos del tronco y del látigo en un lenguaje que procura reproducir la violencia sado-erótica de los señores de esclavo, como en el poema de Fidélis Florencio:

\begin{tabular}{|c|c|}
\hline $\begin{array}{l}\text { Nada de cantigas de Conga- } \\
\text { do. } \\
\text { Conta-me a história daquele } \\
\text { sinhô } \\
\text { Que te cortou de rabo de tatu. } \\
\text { - Chega sinhô! } \\
\text { - Não chega não, negra à toa! } \\
\text { E lépo e lépo e lépo! } \\
\text { E tu pelada no tronco } \\
\text { Como um morcego de ma- } \\
\text { minha, } \\
\text { Mãe Preta: Como se chamava } \\
\text { Esse sinhô tão bravo?. }\end{array}$ & $\begin{array}{l}\text { Nada de canciones de Con- } \\
\text { gado. } \\
\text { Cuéntame la historia de aquel } \\
\text { señor } \\
\text { Que te hirió con cola de ar- } \\
\text { madillo. } \\
\text { - B Basta señor! } \\
\text { - Qué no, !negra desgraciada! } \\
\text { Y lépo y lépo y lépo! } \\
\text { Y tú, desnuda en el tronco } \\
\text { Como un murciélago, } \\
\text { Madre Negra: Como se lla- } \\
\text { maba } \\
\text { Ese señor tan bravo? } \\
\text { (Trad. Malu Otero y Fredy } \\
\text { Valiente) }\end{array}$ \\
\hline
\end{tabular}

En 1928, Jorge de Lima, un poeta de Alagoas que participa del movimiento de vanguardia en el nordeste de Brasil, publica Essa Negra Fulô, obra que presenta la esclavitud como la integral posesión del ser, subrayando lo perverso del castigo sin culpa a que eran sometidos los esclavos muchas veces, hecho señalado por el experimentalismo formal que inserta estrofas de narrativas populares, denunciando la no culpabilidad de Fulô. No deja de señalar el encanto producido por la negra que da origen al mulato en el proceso de mestizaje. 


\section{Essa negra fulô}

\section{Jorge de Lima}

Ora, se deu que chegou
(isso já faz muito tempo)
No bangüê dum meu avô
Uma negra bonitinha
Chamada negra Fulô.
Essa negra Fulô!
Essa negraFulô!
Ó Fulô! Ó Fulô!
(Era a fala da Sinhá)
-Vai forrar a minha cama,
pentear os meus cabelos,
Vem ajudar a tirar
a minha roupa, Fulô!
Essa negraFulô!

Essa negrinha Fulô.

Ficou logo pra mucama

pra vigiar a Sinhá,

pra engomar pro sinhô!

Essa negra Fulô!

Essa negra Fulô!

\section{Ó Fulô! Ó Fulô!}

(Era a fala da Sinhá).

Vem me ajudar, ó Fulô,

Vem abanar o meu corpo

Que eu estou suada, Fulô!

Vem coçar minha coceira,

Vem me catar cafuné,

Vem balançar minha rede,

Vem me contar uma história,

Que eu estou com sono, Fulô!

Essa negra Fulô!

"Era um dia uma princesa, que vivia num castelo:
Pues bien, aconteció que llegó

(y eso ya hace mucho tiempo)

En el ingenio de mi abuelo

Una negra muy guapita

Llamada negra Fro.

¡Esa negra Fro!

¡Esa negra Fro $i$

¡Óye Fro! ¡Óye Fro!

(Era el habla de la Señora) -

Arréglame la cama,

Péiname el pelo,

Ven, !ayúdame aquitarme

La ropa, Fro!

!Esa negraFro!

Esa negrita Fro,

Pronto se ha vuelto mucama

para vigilar a la Señora,

y almidornarle la ropa al señor

¡Esa negra Fro!

¡Esa negra Fro!

!Oye, Fro! !Oye, Fro!

(Era el habla de la Señora).

Ven a ayudarme, oye Fro,

Ven a abanicar me,

!Que estoy sudada, Fro!

Ven a rascarne la comezón,

Ven a hacerme caricias ,

Ven a balancearme la hamaca,

Ven a contarme una historia,

Que yo estoy con sueño, Fro!

Esa negra Fro!

"Había un día una princesa, que vivía en un castillo:
Que possuía um vestido

Com os peixinhos do mar.

Entrou na perna dum pinto

O Rei-Sinhô me mandou

que vos contasse mais cinco".

Essa negra Fulô!

Essa negra Fulô!

Ó Fulô! Ó Fulô!

Vai botar para dormir

esses meninos, Fulô!

"Minha mãe me penteou, minha madrasta me enterrou pelos figos da figueira

que o sabiá beliscou".

Essa negra Fulô!

Essa negra Fulô!

Ó Fulô! Ó Fulô!

(Era a fala da Sinhá

chamando a negra Fulô).

Cadê meu frasco de cheiro

que teu Sinhô me mandou?

-Ah! Foi você que roubou!

Ah! Foi você que roubou!

Essa negra Fulô!

Essa negra Fulô!

O Sinhô foi ver a negra:

Levar couro do feitor.

A negra tirou a roupa.

O Sinhô disse; Fulô!

(A vista se escureceu

que nem a negra Fulô).

Essa negra Fulô!

Essa negra Fulô!

Ó Fulô! Ó Fulô!

Cadê meu lenço de rendas,

Cadê meu cinto, meu broche,

Cadê meu terço de ouro

que teu Sinhô me mandou?

Ah! Foi você que roubou.
Que poseía un vestido

Con los pececitos del mar.

Entró en la pierna de un pollito

El Rey-Señor me mandó

que le contase cinco más".

Esa negra Fro!

Esa negra Fro!

Oye, Fro! Oye Fro!

Acuesta para dormir

A esos niños, Fro!

"Mi madre me peinó,

mi madrasta me enterró

por los higos de la higuera

que el pájaro pellizcó”.

Esa negra Fro!

Esa negra Fro!

Oye, Fro! Oye Fro!

(Era el habla de la Señora

llamando a la negra Fro).

Dónde están los perfumes

que tu Señor me mandó?

-Ah! Fuiste tú que lo robaste!

-Ah! Fuiste tú que lo robaste!

Esa negra Fro!

Esa negra Fro!

El Señor fue a ver a la negra:

Azotada por el mayoral.

La negra se quitó la ropa.

El Señor dijo; Fro!

(La vista se le oscureció

Como la negra Fro).

Esa negra Fro

Esa negra Fro!

!Oye Fro! !Oye Fro!

Dónde está mi pañuelo de encaje,

Dónde está mi cinturón, mi broche,

Dónde está mi rosario de oro que tu Señor me mandó?

!Ah! Fuiste quien lo robaste. 


\begin{tabular}{l|l}
$\begin{array}{l}\text { Ah! Foi você que roubou. } \\
\text { Essa Negra Fulô! }\end{array}$ & $\begin{array}{l}\text { ¡Ah! Fuiste quien lo robaste. } \\
\text { Esa Negra Fro! }\end{array}$ \\
$\begin{array}{l}\text { O Sinhô foi açoitar } \\
\text { Sozinho a negra Fulô. } \\
\text { A negra tirou a saia } \\
\text { e tirou o cabeção, }\end{array}$ & $\begin{array}{l}\text { El Señor ha ido a azotar } \\
\text { Solito a la negra Fro. } \\
\text { Le dentro dele pulou. }\end{array}$ \\
$\begin{array}{l}\text { Nuinha a negra Fulô. } \\
\text { Essa negra Fulô! } \\
\text { Essa negra Fulô! }\end{array}$ & $\begin{array}{l}\text { Y se quito la blusita, } \\
\text { Desde el interior saltó } \\
\text { Desnudita la negra Fro. }\end{array}$ \\
Esa negra Fro \\
$\begin{array}{l}\text { Osa Fulô! Ó Fulô! } \\
\text { cade, cadê teu Sinhô Fro } \\
\text { Que Nosso Senhor me man- } \\
\text { dou? } \\
\text { Ah! Foi você que roubou, } \\
\text { Foi você, negra Fulô? }\end{array}$ & $\begin{array}{l}\text { ¿ue Nuestro Señor me man- } \\
\text { dó? } \\
\text { Ah! Fuiste quien me lo robó, } \\
\text { Fuiste tu, negra Fro? }\end{array}$
\end{tabular}

(Trad. Malu Otero y Fredy Valiente)

Farias (2003:58) presenta otra lectura de Essa Negra Fulô, considerando que el carácter angelical del personaje dado por el diminutivo "bonitinha" va cediendo lugar a todo un aspecto satánico y lo subraya:

El carácter demoníaco en "Essa Negra Fulô" representa la propia salvación del elemento africano que sólo recupera su digna condición humana por intermedio de la usurpación y de la apropiación de los objetos en poder de la clase dominadora. (Farias, 2003:59)

Existe, pues, la posibilidad de más de una interpretación en cuanto a la culpabilidad o no de Fulô. Sin embargo, hay la concordancia en el reconocimiento de un sistema de dominación del hombre por el hombre (esclavitud), la imposición de castigos y el cruce de razas.

La historia de esa parcela de la población brasileña, los negros o mestizos, se ve marcada tras la abolición por la pobreza y el prejuicio racial. Sin embargo, culturalmente ejercen un papel de dominancia en los patrones estéticos musicales, en la literatura, en la visión de mundo del país marcada por el lenguaje, signo de lo fuerte que ha sido la presencia del negro en la formación del caldo cultural brasileño.
Ser negra (preta) es enfrentarse con una serie de dificultades, en una sociedad en que los negros se han visto liberados de la esclavitud, pero sin acceso, de pronto, a bienes materiales, a la educación y a puestos de trabajo que exigieran cualificación.

En 1944, Solano Trindade (1908-1974), poeta pernambucano, estrena con el libro "Poemas d'uma Vida Simples", con protestas frente a las injusticias y prejuicios raciales. En 1961, publica "Cantares ao Meu Povo", poesías que, según Damasceno (1988:75), se componen del cruce de los recuerdos de los sufrimientos de la Esclavitud negra, la denuncia del desprecio social contemporáneo y la herencia africana de la formación cultural brasileña.

En la poesía "Quem tá gemendo?" Solano Trindade remite al dolor provocado por el castigo, por la violencia y la opresión.

\begin{tabular}{l|l} 
“Quem tá gemendo? & “Quién está gimiendo? \\
Negro ou carro de Boi. & Negro o carreta de Buey. \\
Carro de boi geme quando & $\begin{array}{l}\text { Carreta de buey gime cuando } \\
\text { quiere, }\end{array}$ \\
quer, & Negro no \\
Negro não. & Negro gime porque le pegan, \\
Negro geme porque apanha, \\
apanha pra não gemer."
\end{tabular}$\quad$\begin{tabular}{l} 
le pegan para que no gima." \\
\hline
\end{tabular}

(Trad. Malu Otero y Fredy Valiente)

Solano Trindade afirma su posición como negro y señala en su poesía "Sou Negro" la herencia cultural africana que permea la cultura brasileña. Según Damasceno (1988:81), Solano Trindade hace su búsqueda de identidad en la reafirmación del color y de los valores negros; no busca la lucha de razas, sino más bien la integración por el desarrollo cultural.

\begin{tabular}{|c|c|}
\hline $\begin{array}{l}\text { "Sou negro, } \\
\text { meus avós foram queimados }\end{array}$ & $\begin{array}{l}\text { "Soy negro, } \\
\text { mis abuelos fueron quema- } \\
\text { dos }\end{array}$ \\
\hline pelo sol da África & por el sol de África. \\
\hline $\begin{array}{l}\text { Minha'alma recebeu o batis- } \\
\text { mo dos tambores, } \\
\text { atabaques, gongês, agogôs. }\end{array}$ & $\begin{array}{l}\text { Mi alma recibió el bautismo } \\
\text { de los tambores, } \\
\text { tumbas, bongoes y congas. }\end{array}$ \\
\hline $\begin{array}{l}\text { Na minha'alma ficou } \\
\text { o samba }\end{array}$ & $\begin{array}{l}\text { En mi alma todo fue } \\
\text { la samba, }\end{array}$ \\
\hline
\end{tabular}


\begin{tabular}{l|l} 
o batuque & el tamborileo, \\
o bamboleio & $\begin{array}{l}\text { la oscilación } \\
\text { e o desejo de libertação." }\end{array}$ \\
Y el deseo de liberación. "
\end{tabular}

Eduardo de Oliveira (1926-2012), nacido en São Paulo, publicó Banzo en 1965, libro de poesías en que reflexiona sobre la trayectoria del negro brasileño, bastante dramática, por la falta de competitividad en la sociedad brasileña. En 1967 publica Gestas Líricas da Negritude, a la que pertenece la poesía presentada a seguir:

\begin{tabular}{|c|c|}
\hline $\begin{array}{l}\text { O negro não pode continuar } \\
\text { estagnado, }\end{array}$ & $\begin{array}{l}\text { El negro no puede seguir es- } \\
\text { tancado, }\end{array}$ \\
\hline Sem a hematose da cultura & $\begin{array}{l}\text { Sin la hematosis de la cul- } \\
\text { tura }\end{array}$ \\
\hline $\begin{array}{l}\text { Que alimenta e vivifica os } \\
\text { homens }\end{array}$ & $\begin{array}{l}\text { Que alimenta y vivifica a los } \\
\text { hombres }\end{array}$ \\
\hline $\begin{array}{l}\text { O negro, nas vossas articu- } \\
\text { lações ascensionais, }\end{array}$ & $\begin{array}{l}\text { El negro, en vuestras articu- } \\
\text { laciones ascensionales, }\end{array}$ \\
\hline $\begin{array}{l}\text { Não é para ser tido unica- } \\
\text { mente }\end{array}$ & $\begin{array}{l}\text { No debe de ser tenido úni- } \\
\text { camente }\end{array}$ \\
\hline Como graxa lubrificadora; & Como grasa lubricadora; \\
\hline Não deve ser visto, apenas, & No debe ser visto, apenas, \\
\hline $\begin{array}{l}\text { Como substrato básico, } \\
\text { como húmus, }\end{array}$ & $\begin{array}{l}\text { Como substrato básico, } \\
\text { como humus, }\end{array}$ \\
\hline Que, no coração das terras, & $\begin{array}{l}\text { Que, en el corazón de las } \\
\text { tierras, }\end{array}$ \\
\hline Tece o tapete verde & Teje la alfombra verde \\
\hline 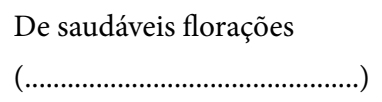 & 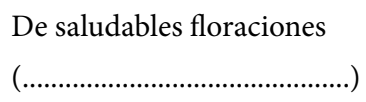 \\
\hline Brasil! & Brasil! \\
\hline $\begin{array}{l}\text { Socorrei-o enquanto é tem- } \\
\text { po" }\end{array}$ & $\begin{array}{l}\text { Socorredlo mientras hay } \\
\text { tiempo" }\end{array}$ \\
\hline & $\begin{array}{l}\text { (Trad. Malu Otero y Frec } \\
\text { Valiente) }\end{array}$ \\
\hline
\end{tabular}

José Carlos Limeira nació en Bahia (Salvador), en 1951. Es otro poeta contemporáneo que explora los caminos de una poesía actual, arraigada al sentimiento de negritud. Integra en su obra el coloquialismo, incorporando elementos de la oralidad. Crea un discurso polifónico y cubre una temática amplia, presentándolo todo desde la perspectiva del negro. Maca (2010) lo califica como un poeta negro que verbaliza con belleza y pujanza, experiencias ejemplares en una tierra camuflada por la ideología del blanqueamiento.
Se observa en José Carlos Limeira el mismo tratamiento de choque empleado ya en Leite Criôlo, enseñándonos una actitud crítica hacia el mundo, hacia la sociedad brasileña y el prejuicio que se oculta, que se dice no existir.

\begin{tabular}{|c|c|}
\hline Queria ver você negro & Queria verte como negro \\
\hline negro queria te ver & negro quería verte \\
\hline se Palmares ainda vivesse & si Palmares aún viviese \\
\hline em Palmares queria viver. & en Palmares quería vivir. \\
\hline O ódio do feitor & El odio del caporal \\
\hline é pegajoso, fecundo & es pegajoso, fecundo \\
\hline ele pode emprenhar & él puede empreñar \\
\hline até as mentes mais estéreis & $\begin{array}{l}\text { incluso las mentes más } \\
\text { estériles }\end{array}$ \\
\hline com seu pênis de chicote & con su verga de chicote. \\
\hline $\begin{array}{l}\text { Já pensou naquele país da se- } \\
\text { rra da Barriga? }\end{array}$ & $\begin{array}{l}\text { ¿Ya pensaste en aquel país } \\
\text { de la sierra deVientre? }\end{array}$ \\
\hline sei que talvez não, & Sé que tal vez no, \\
\hline uma terra & una tierra \\
\hline onde não fosse possível ver & donde no fuera posible ver \\
\hline $\begin{array}{l}\text { uma negra ter que mostrar a } \\
\text { bunda }\end{array}$ & $\begin{array}{l}\text { una negra tener que mostrar } \\
\text { la nalga }\end{array}$ \\
\hline abrir as coxas & abrir los muslos \\
\hline tirar das entranhas & sacar de las entrañas \\
\hline o pão de cada dia & el pan de cada día \\
\hline $\begin{array}{l}\text { Por menos que conte a his- } \\
\text { tória }\end{array}$ & $\begin{array}{l}\text { Por menos que cuente la his- } \\
\text { toria }\end{array}$ \\
\hline não te esqueço meu povo & no te olvido mi pueblo \\
\hline se Palmares não existe mais & si Palmares no existe ya \\
\hline faremos Palmares de novo & haremos Palmares de nuevo \\
\hline & Ouilombo \\
\hline Quilombo & Quilombo \\
\hline Meus sonhos & mis suenos, \\
\hline Sofro de uma insônia eterna & $\begin{array}{l}\text { sufro de un insomnio } \\
\text { eterno: }\end{array}$ \\
\hline De viver vocês & De vivir ustedes \\
\hline (Quilombos) & (Quilombos). \\
\hline
\end{tabular}

(Trad. Malu Otero y Fredy Valiente)

Forma parte de su universo la convivencia con rituales y costumbres afro-brasileñas, presentes en la comida, la música, la capoeira, el samba de roda, el candomble con sus rituales. Bahia es marcada por 
la presencia de lo negro en todos los ámbitos. En el fragmento de la poesía abajo se ve una referencia a Zé Pilintra, a quien se hace el culto en la umbanda. La poesía de Limeira tiene el coloquialismo como cemento, que la estructura de acuerdo a la personalidad de Zé Pilintra.

Tou contigo seu Zé

Teu papo de corimba

Protegendo invisível da rua

Porque da lua somos

Fico mais na minha

Qual é a tua pilintra

Vamos nessa, nesse verso

Vai dar pé.

Tou contigo seu Zé.

(Pro seu Zé)

(Trad. Malu Otero y Fredy Valiente)

En la umbanda uno de los puntos (canciones ritualísticas) es:

Ze Pilintra, Punhal de Aço (cuchillo de acero), que describe esa entidad que encarna la figura del "malandro", el buen vividor, bohemio y que auxilia a uno a abrir los caminos y los protege, sana, desata y deshace cualquier maleficio.

De terno branco, seu pun-

hal de aço puro

O seu ponto é seguro

Quando vem pra trabalhar

Segura o nego, que esse nego é zé pilintra

$\mathrm{Na}$ descida do morro ele vem trabalhar

De traje blanco, su puñal
de acero puro
Su invocación es segura
Cuando se manifiesta
Agarra el negro, que ese negro
Es José Pilintra
Por la bajada del cerro él viene
para manifestarse

(Trad. Malu Otero y Fredy Valiente)

La umbanda proviene de la cultura afro, sumada a costumbres indígenas, en sincretismo con rituales católicos. Durante un período significativo estuvo prohibida su práctica y ese sincretismo se hizo necesario para su supervivencia. Bastide (1973) lo clasifica de sincretismo en mosaico, dado que permanece en el plano de la coexistencia de objetos discordantes. Sin embargo, considero que en el caso de Bahia hubo, de hecho, una fusión a lo largo del tiempo. Lo podemos observar por ejemplo en la misa nagó, celebrada en la Iglesia de Nossa Senhora do Rosário dos Pretos, en el Pelourinho. Es una misa católica, celebrada por un cura, y en la que toman parte las bahianas, con sus trajes típicos y los cánticos se hacen en nagó.
En Brasil, hace menos de un siglo, la umbanda tuvo su primer registro oficial, aunque su raíz africana es milenaria. Se conjugan en la umbanda las fuerzas de la naturaleza por intermedio de los orixas. La palabra orixa significa corona iluminada o espíritu de luz. Los orixas son elementos de la naturaleza, representan puntos de fuerza en ella y son provenientes de la tierra, del aire, del agua y del fuego. La energía proviene, pues, de la naturaleza y los orixas son el camino para canalizarla.

\section{Consideraciones finales}

La poesía negra abarca un universo que cubre los más variados aspectos de la cultura del pueblo (religión, música, comidas, costumbres, lenguaje). Lima (2010) subraya que, cada vez más, implica una nueva conciencia sobre la cuestión del negro, en sus múltiples y complejos aspectos.

La poesía negra de expresión brasileña puede volverse una obra de conjunto, desde que la base sea compartir una misma cultura, una misma realidad de un país mestizo, sin prejuicios raciales o de cualquier otro tipo. Ése es un proyecto que debe tener lugar a cada día, en nuestras acciones en la sociedad.

Lima (2010) afirma que la poesía, al revelar al propio negro, revela al Brasil. Al dejar de ser una pintura extática (como habíamos visto en las poesías al inicio de este trabajo) el negro se vuelve sujeto del proceso. Sin duda, éste es un hecho importante para los cambios y hay mucho por hacer en la construcción de nuestras identidades nacionales.

El negro está conquistando su espacio. Las religiones afros, que eran perseguidas hace un siglo, ahora tienen su práctica liberada y forman parte de la vida y cultura del brasileño. En la educación se practica hoy día el sistema de cuotas para ingreso a la universidad pública e incluso para el ingreso en el servicio público ya existen las cuotas para negros o pardos, como forma de amenizar la injusticia social que han vivido en el pasado.

El respeto por todos los que forman parte de la nación es fundamental y eso significa una lucha diaria por derrumbar ideologías que manipulan e imponen patrones estéticos que nos llegan desde afuera y la conciencia de la importancia que tenemos en conjunto para la consolidación de esa identidad cultural. 


\section{Bibliografía}

BASTIDE, Roger. (1973) As Américas Negras. São Paulo: Difel, Editora da Universidade de São Paulo.

CRUZ, Maria de Lourdes Otero Brabo. (2002) Do negrismo à negritude: comparação entre a República Dominicana e Cuba. In: VII Congresso Internacional ABRALIC 2002, Belo Horizonte: Mediações, 2002.

DAMASCENO, Benedita Gouveia. (1988) Poesia Negra no Modernismo Brasileiro. Campinas: Editora Pontes.

FARIAS, José Niraldo de. (2003). O surrealismo na poesia de Jorge de Lima. Porto Alegre: EDIPUCRS, 2003.

Giras de Umbanda e a cultura afro-brasileira. Acceso em 12/10/2010. In: http://www.girasdeumbanda.com.br/pontosoxossi.asp

LIMA, Luciano Rodrigues (2010) Poesia negra contemporânea: o redescobrimento do Brasil - Discurso poético, consciência e atitude. In http://www2.docentes.uneb.br/.../ POESIA\%20NEGRA\%20CONTEMPORANEA Acceso en 12/10/2010.

MACA, Nelson. Negro homem, negra poesia: José Carlos Limeira. In: http://www.overmundo. com.br/overblog/negro-homem-negra-poesia-jose-carlos-limeira Acceso en 12/10/2010.

NIGRI, André. Rebento bastardo do modernismo, periódico leite criôlo ganha reedição. In: Veja $\mathrm{BH}, 28$ de novembro de 2012. Acceso en mayo de 2014 .

http://vejabh.abril.com.br/edicoes/rebento-bastardo-modernismo-periodico-leite-criolo-ganha-reedicao-722099.shtml

PORTAL DOS ORIXÁS. Acceso en 12/10/2010. http://www.orixas.com.br/index.php?option $=$ com_content $\&$ view $=$ article\&id $=9: 0-$ rixa\&catid $=32:$ languages\&Itemid $=56$ 